\title{
Challenges of urban transport problems and city logistics: Sao Paulo city center case
}

\author{
A. G. L. Peixoto Neto, M. L. Galves, O. F. Lima Júnior \\ \& D. Tacla \\ LALT, Unicamp, Brazil
}

\begin{abstract}
Traffic congestion continues to worsen in South American cities of all sizes, creating a $\$$ billion annual drain on the South American Countries economy in the form of lost hours and gallons of wasted fuel.

The purpose of this work is to provide an overview of urban transport problems and city logistics challenges in Sao Paulo city center. The focus of the discussion is the emerging concept of city logistics to improve the mobility of cities, and the research opportunity that it creates.

Production and consumption have long been central to understanding the evolution and management of transport systems. The current paper argues that there are now some new concepts in that understanding which deserve consideration and will shape a different future.

On the other hand, the organization of logistics has an effect upon the structure of urban areas. At a simple level, global and continental scale logistics systems are organized around airports, seaports, road and rail systems and storage facilities, which all tend to be space extensive.

These challenges are the growth in logistics systems for the globalization of production and consumption, and the related spatial and functional restructuring of large scale urban regions. The core ideas of the paper are that these two changes, associated with innovation and structural change in the economy, have produced concentration as well as dispersal of different types of production and consumption in very large urban regions. They create the need for some new responses in transport planning.
\end{abstract}

Keywords: city logistics, mobility, urban transport and traffic congestion. 


\section{Introduction}

Automobile use is obviously related to a variety of advantages such as demand mobility, comfort, status, speed, and convenience. These advantages jointly illustrate why automobile ownership continues to grow worldwide, especially in urban areas. When given the choice and the opportunity, most individuals will prefer using an automobile. Several factors influence the growth of the total vehicle fleet, such as sustained economic growth (increase in income and quality of life), complex individual urban movement patterns (many households have more than one automobile), more leisure time and suburbanization. The acute growth in the total number of vehicles also gives rise to congestion at peak traffic hours on major thoroughfares, in business districts and often throughout the metropolitan area.

Cities are important generators and attractors of movements, which have created a set of geographical paradoxes that are self-reinforcing. For instance, specialization leads to additional transport demands while agglomeration leads to congestion. Over time, a state of automobile dependency has emerged which results in a diminution in the role of other modes, thereby limiting still further alternatives to urban mobility. In addition to these factors, two major factors contributing to automotive dependency are under pricing, and planning and investment practices.

Most road infrastructures are subsidized as they are considered a public service. Consequently, drivers do not bear the full cost of automobile use. Like the "Tragedy of the Commons", when a resource is free of access (road), it tends to be overused and abused (congestion). This is also reflected in consumer choice, where automobile ownership is a symbol of status, freedom and prestige, especially in developing countries. Single home ownership also reinforces automobile dependency.

Planning and the ensuing allocation of public funds aim towards improving road and parking facilities in an ongoing attempt to avoid congestion. Other transportation alternatives tend to be disregarded. In many cases, zoning regulations impose minimum standards of road and parking services and in reality impose a regulated automobile dependency.

There are several levels of automobile dependency with their corresponding land use patterns and alternatives to mobility [1]. Among the most relevant indicators of automobile dependency are the level of vehicle ownership, per capita motor vehicle mileage and the proportion of total commuting trips made using an automobile [2]. A situation of high automobile dependency is reached when more than three quarters of commuting trips are done using the automobile.

The second half of the 20th century saw the adaptation of many cities in North America and Europe to automobile circulation. Motorized transportation was seen as a powerful symbol of modernity and development. Highways were constructed, streets were enlarged, and parking lots were set often disrupting the existing urban fabric. However, from the 1980s, motorization started to be seen more negatively and several cities implemented policies to limit automobile circulation by a set of strategies described in the next section [3]. 


\section{Strategies to limit automobile circulation}

\subsection{Dissuasion}

Although automobile circulation is permitted, it is impeded by regulations and physical planning. For instance, parking space can be severely limited and speed bumps placed to force speed reduction.

\subsection{Prohibition of downtown circulation}

During most of the day the downtown area is closed to automobile circulation but deliveries are permitted during the night. Such strategies are often undertaken to protect the character and the physical infrastructures of an historical city.

Imposing tolls for parking and entry to some parts of the city is another possible strategy. Most evidence underlines however that drivers are willing to bear additional toll costs, especially when commuting is concerned. Still, congestion pricing is a measure which is increasingly being considered.

Tentative solutions have been put forth such as transport planning measures (synchronized traffic lights, regulated parking), limited vehicle traffic in selected areas, the promotion of bicycle paths and public transit. In Mexico City and Sao Paulo, vehicle use is prohibited according to license plate numbers and the date (even-uneven). Affluent families have solved this issue by purchasing a second vehicle, thus worsening the existing situation. Singapore is the only country in the world which has successfully controlled the amount and growth rate of its vehicle fleet by imposing a heavy tax burden and purchasing permits on automobile owners [1].

There are many alternatives to automobile dependency such as intermodal transport (combining the advantages of individual and transport) or carpooling (strengthened by policy and regulation by the US government). These alternatives, however, can only be partially executed as the automobile remains the prime choice for providing urban mobility. There are however powerful countervailing forces that can influence modal choice, namely congestion.

\subsection{Congestion}

Congestion occurs when transport demand exceeds transport supply in a specific section of the transport system. Under such circumstances, each vehicle impairs the mobility of others.

The last decades have seen the extension of roads in rural but particularly in urban areas. Those infrastructures were designed for speed and high capacity, but the growth of urban circulation occurred at a rate higher than often expected. Investments came from diverse levels of government with a view to provide accessibility to cities and regions. There were strong incentives for the expansion of road transportation by providing high levels of transport supply. This has created a vicious circle of congestion which supports the construction of additional road capacity and automobile dependency. Urban congestion mainly 
concerns two domains of circulation, often sharing the same infrastructures: passengers and freight.

\subsubsection{Passengers}

In many regions of the world incomes have significantly increased to the point that one automobile per household or more is common. Access to an automobile conveys flexibility in terms of the choice of origin, destination and travel time. The automobile is favored at the expense of other modes for most trips, including commuting. For instance, automobiles account for the bulk of commuting trips in the United States.

\subsubsection{Freight}

Several industries have shifted their transport needs to trucking, thereby increasing the usage of road infrastructure. Since cities are the main destinations for freight flows (either for consumption or for transfer to other locations) trucking adds to further congestion in urban areas. The "last mile" problem remains particularly prevalent for freight distribution in urban areas. Congestion is commonly linked with a drop in the frequency of deliveries tying additional capacity to insure a similar level of service.

\section{Infrastructure}

Infrastructure provision was not able to keep up with the growth in the number of vehicles, even more with the total number of vehicles-km. During infrastructure improvement and construction, capacity impairment (fewer available lanes, closed sections, etc.) favors congestion. Important travel delays occur when the capacity limit is reached or exceeded, which is the case of almost all metropolitan areas. In the largest cities such as London, road traffic is actually slower than it was 100 years ago. Marginal delays are thus increasing and driving speed becomes problematic with the level of density. Large cities have become congested most of the day, and congestion is getting more acute. Another important consideration concerns parking, which consumes large amounts of space. In automobile dependent cities, this can be very constraining as each economic activity has to provide an amount of parking space proportional to their level of activity. Parking has become a land use that greatly inflates the demand for urban land.

Daily trips can be either "mandatory" (workplace-home) or "voluntary" (shopping, leisure, visits). The former is often performed within fixed schedules while the latter comply with variable schedules. Mandatory trips are mainly responsible for the peaks in circulation flows, implying that about half the congestion in urban areas is recurring at specific times of the day and on specific segments of the transport system. The other half is caused by random events such as accidents and unusual weather conditions (rain, snowstorms, etc.). As far as accidents are concerned, their randomness is influenced by the level of traffic as the higher the traffic on specific road segments the higher the probability of accidents. The spatial convergence of traffic causes a surcharge of transport 
infrastructures up to the point where congestion can lead to the total immobilization of traffic. Not only does the massive use of the automobile have an impact on traffic circulation and congestion, but it also leads to the decline in public transit efficiency when both are sharing the same roads.

In some areas, the automobile is the only mode for which infrastructures are provided. This implies less capacity for using alternative modes such as public transit, walking and cycling. At some levels of density, no public infrastructure investment can be justified in terms of economic returns. Longer commuting trips in terms of average travel time, the result of fragmented land uses and congestion levels are a significant trend. Convergence of traffic occurs at major highways that serve vast low density areas with high levels of automobile ownership and low levels of automobile occupancy. The result is energy (fuel) wasted during congestion (additional time) and supplementary commuting distances. In automobile dependent cities, the five following measures can help alleviate congestion to some extent [4]:

1- Ramp metering: Controlling the access to a congested highway by letting automobiles in one at a time instead of in groups. The outcome is a lower disruption on highway traffic flows.

2- Traffic signal synchronization: Tuning the traffic signals to the time and direction of traffic flows.

3- Incident management: Making sure that vehicles involved in accidents or mechanical failures are removed as quickly as possible from the road.

4- HOV lanes: High Occupancy Vehicle lanes insure that vehicles with 2 or more passengers (buses, vans, carpool, etc.) have exclusive access to a less congested lane.

5- Public transit: Offering alternatives to driving that can significantly improve efficiency, notably if it circulates on its own infrastructure (subway, light rail, buses on reserved lanes, etc.).

All these measures only partially address the issue of congestion, as they alleviate, but do not solve the problem.

\section{The challenges of public transit}

As cities continue to become more dispersed, the cost of building and operating public transportation systems increases. For instance, only about 80 large urban agglomerations have a subway system, the great majority of them being in developed countries. Furthermore, dispersed residential patterns characteristic of automobile dependent cities make public transportation systems less convenient to support urban mobility. In many cities additional investments in public transit did not result in significant additional ridership. Unplanned and uncoordinated land development has led to rapid expansion of the urban periphery. Residents, by selecting housing in outlying areas, restrict their potential access to public transportation. Over-investment (when investments do not appear to imply significant benefits) and under-investment (when there is a substantial unmet demand) in public transit are both complex challenges.

Urban transit is often perceived as the most efficient transportation mode for urban areas, notably large cities. However, surveys reveal stagnation or a decline 
of public transit systems, especially in North America. The economic relevance of public transit is being questioned. Most urban transit developments had little, if any impacts to alleviate congestion [5] in spite of mounting costs and heavy subsidies. This paradox is partially explained by the spatial structure of contemporary cities which are oriented along servicing the needs of the individual, not necessarily the needs of the collectivity. Thus, the automobile remains the preferred mode of urban transportation. In addition, public transit is publicly owned, implying that it is a politically motivated service that provides limited economic returns. Even in transit-oriented cities such as in Europe, transit systems depend massively on government subsidies. Little or no competition is permitted as wages and fares are regulated, undermining any price adjustments to changes in ridership. Thus, public transit often serves the purpose of a social function ("public service") as it provides accessibility and social equity, but with limited relationships with economic activities. Among the most difficult challenges facing urban transit, the following ones can be mentioned:

\subsection{Decentralization}

Public transit systems are not designed to service low density and scattered urban areas that are increasingly dominating the landscape. The greater the decentralization of urban activities, the more difficult and expensive it becomes to serve urban areas with public transit.

\subsection{Fixity}

The infrastructures of several public transit systems, notably rail and metro systems are fixed, while cities are dynamical entities, even if the pace of change can take decades. This implies that travel patterns tend to change and that a transit system built for servicing a specific pattern may eventually face "spatial obsolescence".

\subsection{Connectivity}

Public transit systems are often independent from other modes and terminals. It is consequently difficult to transfer passengers from one system to the other.

\subsection{Competition}

In view of cheap and ubiquitous road transport systems, public transit faces strong competition. The higher the level of automobile dependency, the more inappropriate the public transit level of service. The public service being offered is simply outpaced by the convenience of the automobile.

\section{City logistics}

City logistics is a relatively new field of investigation brought by the challenges of moving growing quantities of freight within metropolitan areas. According to 
the Institute of City Logistics [6], city logistics is "the process for totally optimizing the logistics and transport activities by private companies in urban areas while considering the traffic environment, the traffic congestion and energy consumption within the framework of a market economy." Simplistically, it concerns the means to achieve freight distribution in urban areas, by improving the efficiency of urban freight transportation, reducing traffic congestion and mitigating environmental impacts.

City logistics, as a distributional strategy, can take many forms. A high density and congested central city can be serviced by an independent freight distribution system calling from a terminal located at the margin. The vehicles used to service the customers (either for deliveries or pickups along a flexible route) are likely to be smaller and thus better adapted for distribution in an urban environment. The urban terminal itself could be a neutral facility interfacing with a set of distribution centers, each of which being connected to their respective supply chains. Thus, a wide array of supply chains connected to the city can achieve a better distributional efficiency within the central city.

The concept of city logistics has emerged to address a new area in transport planning. The objective of the concept is to support the sustainable development of cities and to address challenging problems such as high levels of traffic congestion, negative environmental impacts, high energy consumption and a shortage of trained labor. City logistics is the process of totally optimizing urban logistics activities by considering the social, environmental, economic, financial and energy impacts of urban freight movement.

\subsection{Objectives of city logistics}

In order to be able to understand the complexities of freight transport in urban areas, it is necessary to conduct an examination of various logistics arrangements.

There are essentially four different groups of actors taking part in the logistical process and transport arrangements. The city logistics challenges can be illustrated by the key objective and sub-objective considering the four majors stakeholders as following: shippers, freight carriers, residents (consumers) and administrators.

\subsection{Benefits of city logistics}

The organization of logistics has an effect upon the structure of urban areas. At a simple level, global and continental scale logistical systems are organized around airports, seaports, road and rail systems and storage facilities, which all tend to be space extensive.

The benefits of city logistics considering the actual challenge of urban transportation are:

- Improved productivity and efficiency of logistics service providers.

- Reduced number of transport movements and deliveries per retailer.

- Improved customer service.

- Improved traffic situation 
- Reduced air pollution and noise emission.

- Higher land productivity

\section{New form of goods organization}

\subsection{Distribution centre}

On the basis of structures described before, the question was brought up, whether the delivery vehicles with a destination in the city centre could not be collected at goods distribution centers (city terminal) and thus be able to achieve an effective distribution. The goods distribution centers would thus become a concentration point in the transport chain. Connected with goods distribution centers is the hope that freight transport inside urban areas could be substantially reduced. Particularly the problem of the receiver, who has no coordinated logistics and causes many trips, could be diffused.

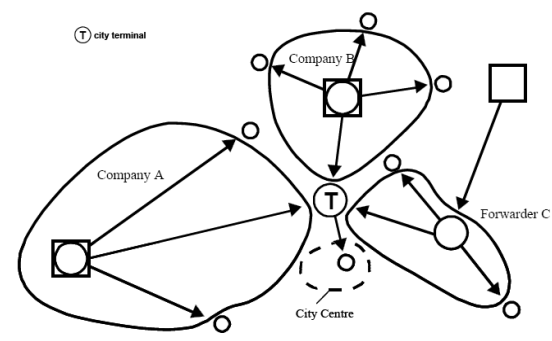

Figure 1: Distribution centre: concentration point in the transport chain.

\subsection{Example of access restrictions and consolidation of delivery in Sao Paulo}

Looking at the environmental aspects of distribution by van or lorry in Sao Paulo city centre is a relatively new concept. Basically, everybody wants lively and accessible city centres where we can all move around safely and where trade and culture are flourishing. This requires delivery of goods on a daily basis. However, so far the distribution of goods has not been in accordance with our wishes regarding the city's space and environment. Sustainable city logistics solutions could be one of the solutions to the problems in the city centres.

The access restrictions which were implemented in the Sao Paulo city centre and in the broader city area within the motorway ring in the 1990s are not strictly obeyed and do not fully ensure efficient, sustainable and for citizens a friendly freight transport. There are several logistics centers in Sao Paulo city which are situated in different locations in the city and cause a large number of transport operations and predictably lower load factor than would be possible.

The main goal of this example in Sao Paulo city is to develop new solutions to improve the organization of goods distribution by identifying acceptable measures of access restrictions and incentives as well as possibilities for 
optimization of freight transport and distribution centers. New logistics concept will be identified by using experiences from other cites and a new sustainable city logistics system will be developed. The identified measures will be taken into consideration in order to achieve the best solutions for Sao Paulo city.

The case is about "How to make the goods transportation more efficient in Sao Paulo city?"

The investigation was carried out by observations and researches obtained from the Sao Paulo City Engineering Traffic Company - CET [7].

The results of this investigation show that:

- It is possible to make the delivery of goods more efficient.

- A large theoretical potential for reducing the haulage in the city is possible.

The studies show that:

- Many conflicts seem to appear between the city centre's function as a commercial zone and as an area where people live, shop and relax.

- The lack of available space in the inner city can be regarded as one of the major city problems and underlines the demand for appropriate solutions.

\subsubsection{Project proposals}

\subsubsection{Cooperation on delivery of goods in the city centre}

- Creation of a local user group to establish a forum where public authorities, the police, transport suppliers and good receivers (shopkeepers) can discuss ideas and find solutions on efficient goods transport that will benefit most of the partners involved.

- In cooperation, transport companies, shopkeepers and local authorities are trying to find solutions for reasonable delivery times.

- All experiments are based on voluntary basis.

- Transport coordination between transport companies.

- Two men in one vehicle - faster delivery of the goods in the city centre.

- Establishing passing places/ loading zones in the pedestrian areas.

6.2.1.2 Delivery vans over $2,500 \mathrm{~kg}$ will be required to have a certificate in oder to stop in the heart of Sao Paulo city centre The number of lorries (truck) and delivery vans has steadily increased in number making it difficult to navigate in the Centre City's small winding streets and leading to increasing traffic congestion.

For these reasons, this project has been proposed to the political arm of the Municipality of Sao Paulo city to implement a two year obligatory trial ordinance - the City Goods Ordinance - with the goal of reducing the number and/or size of the lorries and delivery vans that drive in the city centre.

There are three types of City Goods Certificates:

-The Green Certificate - costs $\mathrm{R} \$ 130$ (50€) and is valid for the entire twoyear trial period. In order to be eligible for the green certificate, $60 \%$ of the vehicle's cargo carrying capacity must be utilized. Additionally, the vehicle's engine must not be older than 8 years. The Green certificate gives exclusive rights to use 20 special loading zones that are established in connection with the City Goods Ordinance. 
-The Yellow Certificate - costs $\mathrm{R} \$ 130$ (50€) and is valid for 6 months. This certificate serves as an option for those vehicles that cannot meet the Green Certificate's restrictions.

-The Red Certificate - costs $\mathrm{R} \$ 20(8 €)$ and is valid for one day. This certificate is meant as a service for those deliveries that only occasionally come into the innermost parts of Sao Paulo Centre. The Red Certificate may be bought at the City Hall Goods Secretariat as well as at petrol stations found on the streets that lead into the designated area in Sao Paulo

\section{References}

[1] Newman, P. and J. Kenworthy (1999) Sustainability and Cities: Overcoming Automobile Dependence, Washington, DC: Island Press.

[2] Victoria Transport Policy Institute (2002) Automobile Dependency, Transport Demand Management Encyclopedia.

[3] Marcadon, J., E. Auphan and A. Barre (1997) Les Transports, Paris: A. Colin.

[4] Texas Transportation Institute (2003) 2003 Urban Mobility Report: Volume 2 Five Congestion Reduction Strategies and Their Effects on Mobility.

[5] Cox, W. (1998) Light Rail in Minneapolis: A Bridge to Nowhere, The Public Purpose, Urban Transport Fact Book.

[6] Institute for City Logistics http://www.citylogistics.org/.

[7] Companhia de Engenharia de Tráfego http://www.cetsp.com.br/. 